\title{
Cerebral near-infrared spectroscopy as a measure of nociceptive evoked activity in critically ill infants
}

\author{
Manon Ranger RN PhD(c) ${ }^{1}$, Celeste C Johnston N DEd FCAHS ${ }^{1,2}$, \\ Catherine Limperopoulos $\mathrm{PhD}^{3,4}$, Janet E Rennick RN PhD ${ }^{5}$, Adre J du Plessis MBChB MPH ${ }^{3,6}$
}

\begin{abstract}
M Ranger, CC Johnston, C Limperopoulos, JE Rennick, AJ du Plessis. Cerebral near-infrared spectroscopy as a measure of nociceptive evoked activity in critically ill infants. Pain Res Manage 2011;16(5):331-336.

Signs of pain may be subtle or absent in a critically ill infant. The complex nature of pain may further obscure its identification and measurement. Because the use of monitoring and neuroimaging techniques has become more common in pain research, an understanding of these specialized technologies is important. Near-infrared spectroscopy (NIRS) is a noninvasive technique for monitoring tissue hemodynamics and oxygenation. There are indications that NIRS is capable of detecting the cerebral hemodynamic changes associated with sensory stimuli, including pain, in infants. These developments suggest that NIRS may play an important role in research focusing on pain perception in critically ill infants. The present review briefly describes the cortical responses to noxious stimuli, which parallel cerebral hemodynamic responses to various stimuli. This is followed by an overview of NIRS technology including a summary of the literature on functional studies that have used NIRS in infants. Current NIRS techniques have well-recognized limitations that must be considered carefully during the measurement and interpretation of the signals. Nonetheless, until more advanced NIRS techniques emerge, the current devices have strengths that should be exploited.
\end{abstract}

Key Words: Infants; Near-infrared spectroscopy; Neurodiagostic technique; Nociception; Pain

Dain is a subjective symptom that, under normal circumstances, triggers a predictable set of objective signs, such as facial grimacing and increased heart rate. Because pain is a warning signal of imminent or ongoing tissue injury, its behavioural manifestations signal to caregivers the need for urgent attention (1). However, in a critically ill infant, the typical signs of pain may be subtle or absent. Their identification and measurement based on observations of behavioural or nonspecific physiological signals remain limited. The difficult task of identifying and decoding the infantile form of self-report is complicated by the fact that the nature of the behavioural signals may vary across the developmental stages of infancy $(1,2)$. Furthermore, in critically ill infants, their fragile and immature state may lessen their capability to organize and exhibit perceived pain as a recognizable response.

Consequently, clinical researchers have explored the use of associated signals to identify pain. As the use of monitoring and neuroimaging techniques becomes more common in pain research, an understanding of their strengths and limitations is important for professionals considering their application for the study and management of critically ill infants.

To evaluate pain in critically ill infants, health care professionals often rely on unstable and nonspecific physiological indicators such as heart rate, arterial oxygen saturation and blood pressure. These parameters could be viewed as more 'objective' or quantifiable than more qualitative behavioural indicators. However, relying on physiological

\section{La spectroscopie proche infrarouge du cerveau pour mesurer l'activité évoquée par une stimulation nociceptive chez des nourrissons gravement malades}

Les signes de douleur peuvent être discrets ou inexistants chez le nourrisson gravement malade. La nature complexe de la douleur peut en compliquer davantage la détermination et la mesure. Puisque les techniques de surveillance et de neuro-imagerie sont davantage utilisées dans le domaine de la recherche sur la douleur, il est important de comprendre ces technologies spécialisées. La spectroscopie proche infrarouge (SPIR) est une technique non invasive pour surveiller l'hémodynamique et l'oxygénation des tissus. Selon certaines indications, la SPIR peut permettre de déceler les modifications hémodynamiques du cerveau associées aux stimuli sensoriels, y compris la douleur, chez les nourrissons. Selon ces observations, la SPIR pourrait jouer un rôle important dans la recherche axée sur la perception de la douleur chez les nourrissons gravement malades. La présente analyse contient une brève description des réponses corticales aux stimuli nuisibles, parallèles aux réponses de l'hémodynamique cérébrale à divers stimuli. Ces constats sont suivis d'un aperçu de la technologie de la SPIR, y compris un sommaire des publications sur les études fonctionnelles qui ont fait appel à la SPIR chez les nourrissons. Les techniques de SPIR actuelles comportent des limites bien connues, qu'il faut évaluer soigneusement lors de la mesure et de l'interprétation des signaux. Néanmoins, tant que des techniques de SPIR plus avancées n'auront pas émergé, les appareils existants comportent des qualités qu'on devrait exploiter.

markers can lead to misinterpretation of pain intensity because they have been shown to decrease the internal consistency of many multidimensional pain assessment instruments and are not specific to the pain response $(3-7)$.

Inaccuracies in pain assessment might be surmounted in the near future as techniques that provide a window into human cerebral responses enable more direct measurement of pain perception (8). Recent studies in premature and term infants indicate that painful stimuli cause circulatory and metabolic changes in specific cortical and subcortical regions of the brain (9-11). Near-infrared spectroscopy (NIRS) is a noninvasive technique that can be used to detect subtle changes in brain concentrations of oxygenated and deoxygenated hemoglobin $\left(\left[\mathrm{HbO}_{2}\right]\right.$ and $[\mathrm{HbH}]$, respectively), which are inferred to reflect changes in cerebral metabolism and perfusion. Recently, it has been demonstrated, using NIRS, that cerebral hemodynamic changes (presumably due to cortical activation) occur in response to stressful and/or painful stimuli in both term and preterm newborn infants (9-12).

Promising results have been reported for the use of noninvasive electroencephalography $(13-15)$ and neuroimaging techniques to measure sensory input processing (16) such as in studies investigating somatosensory and frontal cortex activation (ie, functional magnetic resonance imaging [fMRI] and positron emission tomography) $(17,18)$. Nevertheless, NIRS has an additional feature, compared with MRI and positron emission tomography devices, of being directly portable

${ }^{1}$ School of Nursing, McGill Universtiy, Montreal, Quebec; ${ }^{2}$ IWK Health Centre, Halifax, Nova Scotia; ${ }^{3}$ Division of Fetal and Transitional

Medicine; ${ }^{4}$ Division of Diagnostic Imaging and Radiology, Children's National Medical Center, Washington DC, USA; ${ }^{5}$ Montreal Children's

Hospital, McGill University Health Centre, Montreal, Quebec; ${ }^{6}$ Department of Neurology, Children's Hospital Boston, Boston,

Massachusetts, USA

Correspondence: Manon Ranger, School of Nursing, McGill University, 3506 University Street, Montreal, Quebec H3A 2 A7.

Telephone 514-299-0187, e-mail manon.ranger@mail.mcgill.ca 
to the bedside, which enables continuous signal recording capable of capturing responses to intermittent stimuli. It would appear that there are new and exciting avenues for the assessment of nociception that may be more sensitive and, perhaps, more specific to the pain response for populations such as premature and term infants or critically ill children.

Additional studies are necessary to determine the feasibility, usefulness, specificity, sensitivity and, perhaps most importantly, the clinical significance of these novel physiological assessment instruments in different painful conditions. Among other opportunities, this would provide possibilities for establishing the psychometric properties of currently available pain assessment instruments not requiring specialized equipment in critically ill infants. Not only would noninvasive monitoring techniques, such as NIRS, detect pain perception and the respective cortical regions involved in this experience, they may also enable the identification of the most accurate or sensitive observational pain indicators in specific situations $(11,19)$. To date, only one published study has examined the relationship between NIRS with both physiological and behavioural indicators (ie, three facial expressions) from a pain assessment instrument in a population of newborn infants; moderate associations were demonstrated among these variables (11).

In the present article, we briefly describe the cortical responses to noxious stimuli, followed by an overview of NIRS technology and, finally, a literature review of functional activation studies using NIRS in critically ill infants, with a particular emphasis on pain activation studies. The objective is to provide the reader with a better understanding of the technology, its applications in pain research and its potential use in clinical settings.

\section{CORTICAL PAIN RESPONSES}

The brain is the principal processor of internal and external sensory experiences including pain. It receives messages, relays them to the appropriate areas for interpretation and, subsequently, transforms them into appropriate responses (20). Many aspects of the pain experience can be studied including peripheral nociception, central processing, cortical modulation, and cognitive-emotional and psychological qualities. Our understanding of the pain experience has increased through the identification of specific cerebral regions involved in pain processing. It is well established that specific regions implicated in pain processing are located deeper in the brain than others (ie, insula and anterior cingulate cortex) and that to be examined, advanced neuroimaging techniques with high spatial resolution, such as MRI, are required $(17,18)$. Conversely, the primary somatosensory cortex, which is involved in the processing of sensory input, is located more superficially; activity in this cortical region is more accessible to examination by noninvasive optical techniques such as NIRS.

\section{Cortical activation and pain processing}

Emotional and motivational processing at higher cortical levels are necessary for an individual to fully experience pain (21). More primal physiological reactions, such as limb withdrawal and an increase in heart rate, are the result of subcortical level responses of the nervous system, ie, spinal cord, brainstem, hypothalamus and thalamus (22). Behaviours such as facial actions and cry are valued as good proxy measures of the pain experience in individuals who cannot communicate verbally (1). Although these reactions to painful events are a vital part of the pain experience (23), it is unclear whether these cues are true reflections of pain perception and awareness involving cortical processes, or whether they are reflexive (11). Observers use these cues to quantify the internal sensation of pain as a proxy measure, and some even report them as being more honest expressions than self-reports (23). As previously explained, it is recognized that the cerebral cortex is involved in various dimensions of pain perception, such as the sensory and affective components, and these are analyzed in parallel by different areas of the nociceptive system. The question now focuses on determining the specific pain-related functions served within each cortical region and how they interact (21). The role of the primary and secondary somatosensory cortexes in providing a sensory discriminative functional role when activated by noxious stimuli is well established $(17,18)$. Nevertheless, many questions about brain activity responses to noxious stimuli remain unanswered. For example, it is not clear why some infants, in certain circumstances, do not display behavioural reactions to noxious procedures (19).

The presence of specific topographical areas of the cerebral cortex dedicated to pain perception has been extensively studied $(17,24)$. Cumulative evidence has permitted researchers to identify two major neuronal projection pathways for pain transmission from the periphery that start in the nociceptive regions of the spinal cord dorsal horn (laminae I and V). From there, impulses are transmitted to specific areas of the brain by two distinct systems: the lateral thalamus transmits information about the intensity, location and duration of noxious stimuli to the primary and secondary somatosensory cortexes (SI and SII); and the medial thalamic system sends messages regarding affective and motivational dimensions of noxious stimuli to the limbic cortexes (insula and anterior cingulate cortex) $(17,18,24)$.

Other areas of the brain involved in the evaluative cognitive elements of pain have been identified (ie, prefrontal cortex, amygdala, hypothalamus, hippocampus and thalamus), but a comprehensive analysis of all the anatomical areas of the brain that are associated with pain is beyond the scope of the present review. Findings within this field of research have been previously summarized $(17,18,24,25)$.

In brain physiology, it has been appreciated since the late 1890 s that neuronal activity is closely linked to blood flow and metabolism $(26,27)$. This founding principle has set the stage for many important discoveries and has provided the basis for functional brain imaging techniques $(26,28)$. Accordingly, during specific mental or behavioural tasks, changes in the level of hemoglobin oxygenation in specific brain regions are used as indicators of localized brain activity, which transiently alters the oxy-deoxyhemoglobin levels within these regions and can be measured using fMRI (26). Contrary to results seen in adult fMRI studies, young children (younger than five years of age) show an increase in oxygen consumption that outpaces the increase in blood flow after stimulation of specific regions of the brain $(29,30)$. This is the case for both $\left[\mathrm{HbO}_{2}\right]$ and $[\mathrm{HbH}]$ increases. This phenomenon has been tentatively explained by anatomical differences in cerebral neuronal networking in immature regions of the brain. For example, compared with older children (older than six years of age) and adults, there is a higher number of synaptic connections in the immature visual system (30). Thus, cerebral neurovascular coupling could differ in young children compared with more mature neuronal networks found in adults (31).

During baseline brain metabolism, an equilibrium between oxygen use and blood flow is present. Consequently, the cerebral oxygen extraction fraction (OEF), which can be depicted as "the percentage of the oxygen delivered to the brain that is utilized by the brain" (32), is very stable and can be used as a reliable indicator to define baseline brain metabolism. In the awake resting state, brain energy requirements are quite high, accounting for approximately $20 \%$ of the oxygen and glucose use in the whole body, and 10\% of the cardiac output (33). During brain 'activation', there is a modest mobilization of energy (ie, approximately a $10 \%$ increase from baseline activity) characterized by increases in blood flow, glucose use and oxygen delivery. However, the increase in oxygen use is slightly lower than the increase in oxygen delivery, resulting in a relative decrease in OEF because the supply transiently exceeds the demand, reflected by an increase in $\left[\mathrm{HbO}_{2}\right]$ and a decrease in $[\mathrm{HbH}]$. In comparison, a 'deactivation' relates to a transient increase in OEF and represents a decrease in neural activity compared with baseline metabolism, but not all decreases are deactivations $(26,32)$.

These neurovascular and neurometabolic coupling mechanisms support the use of techniques that measure regional cerebral hemodynamic responses to increase our understanding of pain processing at the cortical level. The following section provides a description of NIRS, which is a noninvasive bedside technique for monitoring 
cerebral perfusion and oxygenation. An overview of functional NIRS (fNIRS) research articles within the infant population is also featured, with a particular focus on pain and NIRS studies.

\section{NIRS}

NIRS is an optical technique based on the principle that light in the near-infrared (NIR) range ( $700 \mathrm{~nm}$ to $1000 \mathrm{~nm}$ ) is able to pass through skin, soft tissue and bone with relative ease, and can penetrate brain tissue to a depth of up to $8 \mathrm{~cm}(34,35)$. The depth of penetration of the NIR light is dependent on the thickness and density of the tissue. Accordingly, when illuminating the somatosensory cortex area of the premature infant, the light may enter much deeper, with signals penetrating the primary somatosensory cortex and parts of the secondary somatosensory cortex, insula, cingulate cortex, thalamus and amygdala (34). Due to the thickness of adult skulls, light does not penetrate more than $5 \mathrm{~cm}$ from the surface. The light is mainly absorbed by two chromophores: hemoglobin and cytochrome aa3. A chromophore is a substance that absorbs light of a given wavelength (eg, NIR light spectrum varies between approximately $650 \mathrm{~nm}$ and $1000 \mathrm{~nm}$ ), and those found in living tissues are $\mathrm{HbO}_{2}, \mathrm{HbH}$ and cytochrome oxidase (36). Each of these chromophores has its peak NIR light absorption at a specific distinct wavelength.

The calculation of the chromophore's concentration and absorbance of NIR light in the tissue is made possible by a modified BeerLambert law (37). This law permits the calculation of the attenuation of a light source that passes through a given substance. When light penetrates a medium that is not homogeneous, such as living tissue, it does not simply travel from the source to the receiver - part of its propagation is scattered and lost. Thus, the distance from the light source to the receiving end is affected by a differential pathlength factor (DPF). The DPF has been calculated for various biological tissues, but has also been shown to vary between participants, which may partly explain the complexity in standardizing NIRS variables across participants $(35,37)$.

The hemodynamic signal obtained with the NIRS technique is based on the absorption of NIR light by hemoglobin, which in turn, depends on the oxygenation state of hemoglobin circulating through the tissues. Thus, NIRS measures the relative change in the tissue concentration of intravascular $\mathrm{HbO}_{2}$ and $\mathrm{HbH}(34-36)$.

\section{Cerebral hemodynamics and NIRS}

Research using NIRS to study variations in cerebral oxygenation and hemodynamics of human neonates originated in the work by Brazy et al in 1985 (38). Although there have been significant advances in this field during the past decade, the understanding of how blood flow, metabolism and neuronal activity interact to affect the NIRS signals remains incomplete (34). Establishing the validity of the NIRS measures has also been difficult because few alternative technologies exist to serve as a 'gold standard' (35).

The study of hemodynamic changes to assess the functional activation in the brain is based on the assumption that a given stimulus will induce a neuronal response, which in turn, triggers local vasodilation, with an increase in cerebral blood volume (CBV) and cerebral blood flow (CBF) (36). Using NIRS, we are able to infer changes in cerebral blood flow by measuring changes in the hemoglobin difference, which is obtained by calculating the difference between the changes in $\left[\mathrm{HbO}_{2}\right]$ and $[\mathrm{HbH}]$. As for changes in $\mathrm{CBV}$, they largely reflect the changes in total concentration of hemoglobin or 'total hemoglobin' ([HbT]), which is the sum of $\left[\mathrm{HbO}_{2}\right]$ and $[\mathrm{HbH}](39,40)$. Under these circumstances, an increase in the relative concentration of the $\left[\mathrm{HbO}_{2}\right]:[\mathrm{HbT}]$ ratio suggests that $\mathrm{CBF}$ has increased in excess of oxygen consumption, which is what is expected to happen during a noxious stimulus. This principle illustrates how neural inputs may provoke hemodynamic changes in the cortical area where the 'message' is processed. On the other hand, a decrease in the relative $\left[\mathrm{HbO}_{2}\right]$ and $[\mathrm{HbT}]$ compared with a baseline measure can be interpreted as a regional cortical deactivation (34,41-44) (Table 1). Such observations

\section{TABLE 1}

\section{Summary of hemodynamic measures derived from near-infrared spectroscopy data}

\begin{tabular}{ll}
\hline Name & Formula \\
\hline Total hemoglobin $(\Delta[\mathrm{HbT}])$ & $\Delta\left[\mathrm{HbO}_{2}\right]+\Delta[\mathrm{HbH}]$ \\
Hemoglobin difference $(\Delta[\mathrm{HbD}])$ & $\Delta\left[\mathrm{HbO}_{2}\right]-\Delta[\mathrm{HbH}]$ \\
Cerebral blood flow $(\Delta \mathrm{CBF})$ & $\Delta\left[\mathrm{HbO}_{2}\right]-\Delta[\mathrm{HbH}]=\Delta[\mathrm{HbD}] \cong \Delta \mathrm{CBF}$ \\
Cerebral blood volume $(\Delta \mathrm{CBV})$ & $\Delta\left[\mathrm{HbO}_{2}\right]+\Delta[\mathrm{HbH}]=\Delta[\mathrm{HbT}] \cong \Delta \mathrm{CBV}$ \\
Principle & If $\uparrow \frac{\left[\mathrm{HbO}_{2}\right] \rightarrow \mathrm{CBF}>\mathrm{O}_{2} \text { consumption }}{\left[\mathrm{HbT}^{-}\right]}$ \\
\hline
\end{tabular}

Data measured by the near-infrared spectroscopy technique represent relative changes in the oxygenation state of the hemoglobin $(\Delta)$. Data from references $39,63,65$ and 66

have been described in a study of hemodynamic changes in the olfactory cortex following 'strong odours' stimulation (ie, disinfectant or tape remover substances) in premature infants (45).

\section{Clinical application and fNIRS studies}

NIRS has been providing quantitative data regarding the oxygenation status of living biological tissue since the pioneering work of Jöbsis (46) in the late 1970s. During the past two decades, studies have been conducted to assess the feasibility of this technique for monitoring variations in cerebral oxygenation of patients at risk for brain damage $(34,36)$. NIRS studies can be divided into two categories: measurement of brain activity through assessment of dynamic relative changes in regional cerebral blood flow in real time (continuous wave-type instrument); and imaging of brain activity as a function of time (timeresolved instrument) (47). For additional references about these NIRS techniques, refer to the article by Hoshi (47).

Many advantages of this optical technique have been described. Specifically, it is a safe, noninvasive, bedside technique for exploring pathophysiological mechanisms underlying brain injury in sick infants (48). It has enormous potential as a tool for measuring cerebral hemodynamic responses to a variety of stimuli including changes in blood pressure, oxygenation, carbon dioxide and neuronal activation. The excellent temporal resolution of NIRS makes it a potentially valuable tool for assessing various pathologies and their management. It can be adapted to many experimental and clinical situations, and combined with other electrophysiological and neuroimaging techniques $(34,36,40)$. Currently, it is a clinical and research tool providing anesthesiologists, neurologists, neurosurgeons, physiologists, cardiac surgeons, neonatologists and nurses with important insights into the hemodynamic and oxygenation activity of the brain in adults and children (36). NIRS has been used in studies of brain neurophysiological development and reactivity in preterm and term infants $(12,35,36,49-51)$, as well as in intra- and postoperative cardiac infant studies (52-54). Regarding this last area, NIRS technology has assisted researchers in determining the complex changes in cerebral hemodynamics that persist during the early postoperative period. As such, these ongoing cerebral hemodynamic disturbances may impact cerebral hemodynamic-activation coupling (36), thereby confounding the interpretation of cortical activation by noxious stimuli. Furthermore, certain treatments provided to critically ill infants may have significant effects on cerebral circulation such as surfactant administration, mechanical ventilation, blood transfusion, surgery, hypothermia, analgesics/sedatives, caffeine and indomethacin therapies (34,35,55-57). The effects of these agents on NIRS measurements need to be considered carefully during studies in this complex clinical scenario.

In the past decade, there has been an increase in brain functional activation studies in the newborn evaluating cortical activation to certain stimuli using NIRS technology such as olfactory $(45,58)$, visual $(29,59)$, auditory (34), tactile and pain stimulation (9-11). Brain functional activation studies have opened the door to a whole new area of research. These studies have already provided valuable insights into the functional topography of the different components of the sensory 
system, and this is likely to remain an important approach for future research. Bartocci et al (9), for example, demonstrated that a noxious (ie, venipuncture) stimulus on the hand induced a significant $\left[\mathrm{HbO}_{2}\right]$ increase in the contralateral somatosensory cortex of preterm infants. Because there was no accompanying change in the occipital cortex, this argued against a global, sympathetically mediated response as might be occurring after sudden changes in blood pressure in infants with tenuous cerebral pressure autoregulation, or after a general state change response to pain (50).

Currently, multichannel NIRS devices that can cover multiple regions of the scalp are not readily available, but their application in experimental contexts is increasing in adult and pediatric fNIRS research $(47,60,61)$. Recently, researchers using diffuse optical tomography (a multichannel NIRS device) were able to demonstrate a specific pain signal response in the somatosensory cortex of healthy adults after a noxious thermal stimulation (61). As these techniques continue to advance, obstacles to their application in younger, less healthy populations will likely be reduced. Multichannel NIRS devices bring increasing spatial resolution to the already excellent temporal resolution of NIRS, enabling better functional mapping and providing more insight into brain function (47). For a comprehensive review of the progress and state of NIRS instrumentation and their clinical applications in preterm and term neonates, we invite readers to refer to Wolf and Greisen (48).

\section{NIRS and pain research in critically ill infants}

The literature examining pain and brain functional activation studies in critically ill infants is relatively recent. To date, only three studies reporting on pain and NIRS have been published (9-11), all of which involved preterm and term neonates.

Slater et al (10) were the first to report somatosensory cortical activation following heel lance in a group of 18 newborns who were 25 to 45 weeks' postmenstrual age (each newborn was studied one to five times). They demonstrated a clear distinction between spinal and cortical processing, where strong reflex reactions (ie, spinal) did not automatically correspond to more perceived pain (ie, cortical), as demonstrated with nonsignificant changes in the cerebral total hemoglobin concentration. Notably, these cortical activations were shown to be discriminative to pain because Von Frey hair stimulation (ie, filaments used to measure the threshold for touch-evoked sensation) of the plantar surface of the foot caused a flexion withdrawal response but did not lead to a cortical activation. Thus, spinal reactions could serve as protective reflexes. Increases in $[\mathrm{HbT}]$ in the contralateral somatosensory cortex was found following heel lance in infants as young as 25 weeks of age (mean $[ \pm \mathrm{SD}][\mathrm{HbT}]$ increase of $7.74 \pm 1.10 \mu \mathrm{mol} / \mathrm{L}$ ) and were independent of global hemodynamic changes. Finally, the increases in $[\mathrm{HbT}]$ depended on the gestational age and awake/sleep states of the infants, with less robust contralateral cortical responses in younger neonates than older ones, and in neonates who were asleep versus awake.

Bartocci et al (9) demonstrated specific somatosensory cortical activation to venipuncture in 40 preterm neonates born between 28 and 36 weeks of gestation and with a postnatal age of $25 \mathrm{~h}$ to $46 \mathrm{~h}$. One group of 29 neonates was monitored bilaterally and symmetrically overlying the somatosensory cortex. Tactile and painful stimuli were applied on both sides of the hand (one-half of the group received stimulation on the left hand and the rest received it on the right). In a second group of 11 infants, the contralateral somatosensory and occipital areas were recorded, enabling measurement of the specificity of cerebral regions. Increases in $\left[\mathrm{HbO}_{2}\right]$ in somatosensory areas in both groups occurred after skin disinfection (tactile stimulus) and an even stronger response occurred after venipuncture (noxious stimulus); in the latter group, no changes were detected in the occipital cortex. Thus, differing areas of blood flow indicated a specific response to painful stimulation in the brain. Interestingly, additional findings showed that somatosensory responses to painful stimulation measured with NIRS were more prominent in the cortex of the left hemisphere, of higher intensity in male infants, directly associated with postnatal age, and inversely correlated with gestational age.

Differences in the time sequence of examined changes in oxygen saturation and $\left[\mathrm{HbO}_{2}\right]$, led Bartocci et al (9) to conclude that changes in vital signs did not explain the $\left[\mathrm{HbO}_{2}\right]$ augmentations noted over the somatosensory cortex in their study population. Accordingly, oxygen saturation dropped following venipuncture (lasting $20 \mathrm{~s}$ to $30 \mathrm{~s}$ ), while the cerebral $\left[\mathrm{HbO}_{2}\right]$ significantly increased and remained so for $2 \mathrm{~min}$ to $3 \mathrm{~min}$, well after the changes in vital signs had subsided. Furthermore, even though crying influences cerebral hemodynamics, this behavioural response started to influence cortical circulation after approximately $5 \mathrm{~min}$, whereas the functional activation in the somatosensory areas appeared in the 'silent' phase of this response (between the venipuncture and the observable indicator).

The ongoing search for a 'gold standard' in pain assessment in nonverbal populations, such as critically ill infants, has provided direction for future research. A recent study examining the connection between behavioural pain indicators and cortical activation appears to be a promising approach. Slater et al (11) measured correlations between scores of the Premature Infant Pain Profile (PIPP) pain assessment tool (62) and somatosensory cortical activation to heel lance in 12 infants 25 to 43 weeks of age (33 test occasions). Moderate correlations between the total PIPP score and level of cerebrovascular response were found (regression coefficient $=0.72[95 \% \mathrm{CI} 0.32$ to 1.11], $\mathrm{P}=0.001 ; \mathrm{r}=0.57$ ). Among the different indicators in the PIPP, facial expressions were most highly correlated with changes in $[\mathrm{HbT}]$ (regression coefficient $=1.26[95 \%$ CI 0.84 to 1.67$], \mathrm{P}<0.0001$; $\mathrm{r}=0.74$ ). Importantly, however, in some infants, cortical 'pain' responses occurred without changes in facial expression, stressing the importance of relying on other means of pain assessment in populations with limited observable behavioural displays.

The use of NIRS to study pain perception in humans is relatively recent, and many avenues remain unexplored. Generalizability of findings from the three studies conducted to date is limited (9-11). Sample sizes were small, and possible confounding factors were not accounted for. With the exception of two premature infants receiving morphine during one study (10), there have been scant descriptions of study samples regarding diagnosis, severity of illness, comorbidity and medication administration. Many of these factors could affect cerebral hemodynamics, which in turn, could have altered the results. In future studies, these factors must be carefully accounted for to enhance the general applicability of these findings. In addition, very few data were provided in the three studies conducted to date regarding systemic physiological responses, which are important factors to consider when measuring cerebral hemodynamic responses to noxious stimuli. Only two studies $(9,11)$ provided data regarding heart rate and peripheral arterial blood oxygen saturation compared with cerebral oxygenated and $[\mathrm{HbT}]$ changes. Most importantly, none of the studies provided data related to blood pressure, which is known to be related to CBF and CBV changes during nociceptive events in sick infants $(12,63)$. Advances in this field will depend on the careful measurement and analysis of other simultaneous physiological changes that may confound the interpretation. In addition to factors that have been found to be associated with cerebral hemodynamic changes (ie, gestational age, sex, asleep/awake state), important confounders such as sound and lighting in the neonatal intensive care unit, as well as infants' severity of illness remain unexplored, but should be accounted for in future studies.

\section{Limitations of the NIRS technique}

NIRS technology is not without limitations, some of which may be more difficult to overcome than others. The amount of NIR light reaching the detector optode is influenced not only by the concentration of the absorbing chromophores (eg, hemoglobin), but also the amount of photon scattering. With more scattering, the light has a longer path through the tissues and, therefore, has a greater chance of being absorbed. Currently, a major drawback of most available 
devices is the unknown path length of the NIR light within tissues. For this reason, it is still necessary to apply a constant DPF to the measurements and to assume that this path length does not change significantly during the course of a study. This remains a tenuous assumption in many clinical situations. Tables of differing pathlength factors in brain tissues for different participants are used, but are known to vary significantly with age $(35,37)$. As such, measured data should be regarded as an absolute change in hemoglobin concentration rather than absolute values (34). Another major drawback of NIRS technology is related to the difficulty in accurately identifying the exact region that is sampled by the NIR light (47). However, conducting multichannel fNIRS trials, as mentioned previously, enables a more accurate mapping of cortical areas and improved discrimination (61).

NIRS technology is sensitive to various factors that may confound results. Conditions related to critical illness that may result in metabolic somatosensory changes could confound pain-related activation measurement using NIRS. Environmental stimuli also need to be taken into account when performing fNIRS because they can bias the results. Patient movement can cause artefacts and disruptions in data collection. Nonetheless, this technology has the major advantage of enabling continuous bedside monitoring of cerebral activity and hemodynamics in a noninvasive manner, which is particularly valuable for the critically ill infant. Finally, despite the fact that NIRS has some reliability issues limiting its widespread use for close clinical monitoring of cerebral hemodynamics, it can provide significant insight into the multifaceted physiological and pathological responses to stimuli $(35,61,64)$. Until more advanced NIRS technologies become available, the strengths of the current devices should be exploited and the limitations carefully considered when interpreting data generated by this unique neurodiagnostic technique.

\section{CONCLUSION AND RECOMMENDATIONS FOR FUTURE RESEARCH}

Although our understanding of the multidimensional experience of pain has advanced over the past century, avenues remain unexplored, particularly in vulnerable populations such as noncommunicative patients. NIRS has potential as a technique for assessing pain-evoked cerebral activation in critically ill infants. Given the complexity of NIRS technology, the paucity of research supporting its use in pain measurement in critically ill infants, and the need for tight control of many confounding factors as well as artefacts, more studies are clearly needed. At this stage, it may be best to consider this neurodiagnostic technique solely as a research tool that will improve our understanding of pain perception, increase the psychometric features of currently available pain assessment instruments and, perhaps, assess the efficacy of pharmacological and nonpharmacological treatments.

Determining what constitutes a clinically significant change in the measured parameters (ie, $\left[\mathrm{HbO}_{2}\right],[\mathrm{HbH}]$ and $[\mathrm{HbT}]$ ) compared with normal fluctuations that occur in the brain tissue by sampling both healthy and critically ill infants of differing developmental ages is also needed. Finally, because a variety of devices using NIRS technology are currently available for research (eg, NIRO devices, Hamamatsu Photonics, Japan) and clinical use (eg, INVOS Systems, Somanetics, USA), setting standards for specific use in pain measurement could facilitate the generalization of findings.

A major question that is raised by clinicians caring for noncommunicative patients is whether this technique will move beyond research to become a bedside monitoring technique for pain assessment. Moreover, can this technology help us monitor the cerebral hemodynamic changes due to prolonged pain versus acute procedural pain, and can it make this distinction? When considering the research findings and current available devices, this may seem improbable. Nevertheless, this approach should not be abandoned because its usefulness as a portable means to functional brain mapping is evolving well and setbacks are being resolved $(47,61)$. If the NIRS technique is validated over time as an accurate measure of pain, other issues will arise, as with all proxy measures of pain, such as determining successful analgesic response. All pain indicators for noncommunicating people require a series of validation studies with replication, and NIRS would be no exception.

FINANCIAL SUPPORT: The authors have no conflicts of interest or financial disclosures. Ranger is supported by the Quebec Health Research Fund (FRSQ), the Quebec Interuniversity Nursing Intervention Research Group (GRIISIQ), the Quebec Pain Research Network, and the Ministère de l'Éducation, du Loisir et du Sport. CC Johnston and JE Rennick are also members of the GRIISIQ and of the McGill University Health Centre Research Institute (Montreal, Quebec), which is funded by FRSQ.

\section{REFERENCES}

1. Anand KJS, Craig KD. New perspectives on the definition of pain. Pain 1996;67:3-6.

2. Johnston CC, Stevens BJ. Experience in a neonatal intensive care unit affects pain response. Pediatrics 1996;98:925-30.

3. Carnevale FA, Razack S. An item analysis of the COMFORT scale in a pediatric intensive care unit. Pediatr Crit Care Med 2002:3:177-80.

4. Ista E, van Dijk M, Tibboel D, de Hoog M. Assessment of sedation levels in pediatric intensive care patients can be improved by using the COMFORT "behavior" scale. Pediatr Crit Care Med 2005;6:58-63.

5. Ramelet AS, Rees N, McDonald S, Bulsara M, bu-Saad HH. Development and preliminary psychometric testing of the Multidimensional Assessment of Pain Scale: MAPS. Paediatr Anaesth 2007;17:333-40.

6. van Dijk M, de Boer JB, Koot HM, Tibboel D, Passchier J, Duivenvoorden HJ. The reliability and validity of the COMFORT scale as a postoperative pain instrument in 0 to 3 -year-old infants. Pain 2000;84:367-77.

7. van Dijk M, de Boer JB, Koot HM, et al. The association between physiological and behavioral pain measures in 0 - to 3-year-old infants after major surgery. J Pain Symptom Manage 2001;22:600-9.

8. Anand KJS. Pain assessment in preterm neonates. Pediatrics 2007;119:605-7.

9. Bartocci M, Bergqvist LL, Lagercrantz H, Anand KJ. Pain activates cortical areas in the preterm newborn brain. Pain 2006;122:109-17.

10. Slater R, Cantarella A, Gallella S, et al. Cortical pain responses in human infants. J Neurosci 2006;26:3662-6.

11. Slater R, Cantarella A, Franck L, Meek J, Fitzgerald M. How well do clinical pain assessment tools reflect pain in infants? PLoS Med 2008;5:e129.

12. Limperopoulos C, Gauvreau KK, O'Leary H, et al. Cerebral hemodynamic changes during intensive care of preterm infants. Pediatrics 2008;122:e1006-13.

13. Slater R, Worley A, Fabrizi L, et al. Evoked potentials generated by noxious stimulation in the human infant brain. Eur J Pain 2010;14:321-6.

14. Slater R, Fabrizi L, Worley A, Meek J, Boyd S, Fitzgerald M. Premature infants display increased noxious-evoked neuronal activity in the brain compared to healthy age-matched term-born infants. Neuroimage 2010;52:583-9.

15. Slater R, Cornelissen L, Fabrizi L, et al. Oral sucrose as an analgesic drug for procedural pain in newborn infants: A randomised controlled trial. Lancet 2010;376:1225-32.

16. Klem GH, Luders HO, Jasper HH, Elger C. The ten-twenty electrode system of the International Federation. The International Federation of Clinical Neurophysiology. Electroencephalogr Clin Neurophysiol Suppl 1999;52:3-6.

17. Apkarian AV, Bushnell MC, Treede RD, Zubieta JK. Human brain mechanisms of pain perception and regulation in health and disease. Eur J Pain 2005;9:463-84.

18. Treede RD, Kenshalo DR, Gracely RH, Jones AKP. The cortical representation of pain. Pain 1999;79:105-11.

19. Slater R, Cantarella A, Yoxen J, et al. Latency to facial expression change following noxious stimulation in infants is dependent on postmenstrual age. Pain 2009;146:177-82.

20. Melzack R. From the gate to the neuromatrix. Pain 1999;82(Suppl 1):S121-6. 
21. Hofbauer RK, Rainville P, Duncan GH, Bushnell MC. Cortical representation of the sensory dimension of pain. J Neurophysiol 2001;86:402-11.

22. Slater R, Fitzgerald M, Meek J. Can cortical responses following noxious stimulation inform us about pain processing in neonates? Semin Perinatol 2007;31:298-302.

23. Craig KD, Versloot J, Goubert L, Vervoort T, Crombez G. Perceiving pain in others: Automatic and controlled mechanisms. J Pain 2010;11:101-8.

24. Derbyshire SWG, Osborn J. Modeling pain circuits: How imaging may modify perception. Neuroimaging Clin N Am 2007;17:485-93.

25. Tracey I, Mantyh PW. The cerebral signature for pain perception and its modulation. Neuron 2007;55:377-91.

26. Magistretti PJ. Neuron-glia metabolic coupling and plasticity. J Exp Biol 2006;209:2304-11.

27. Magistretti PJ, Pellerin L. Cellular mechanisms of brain energy metabolism and their relevance to functional brain imaging. Philos Trans R Soc Lond B Biol Sci 1999;354:1155-63.

28. Mazziotta JC, Toga AW, Frackowiak RSJ. Brain Mapping. San Diego: Academic Press, 2000.

29. Meek JH, Firbank M, Elwell CE, Atkinson J, Braddick O, Wyatt JS. Regional hemodynamic responses to visual stimulation in awake infants. Pediatr Res 1998;43:840-3.

30. Marcar VL, Strassle AE, Loenneker T, Schwarz U, Martin E. The influence of cortical maturation on the BOLD response: An fMRI study of visual cortex in children. Pediatr Res 2004;56:967-74.

31. Sava S, Lebel AA, Leslie DS, et al. Challenges of functional imaging research of pain in children. Mol Pain 2009;5:30.

32. Gusnard DA, Raichle ME, Raichle ME. Searching for a baseline: Functional imaging and the resting human brain. Nat Rev Neurosci 2001;2:685-94.

33. Magistretti PJ. Brain energy metabolism. In: Zigmond M, Bloom F, Landis S, Roberts J, Squire L, eds. Fundamental Neuroscience. San Diego: Academic Press, 1999:389-413.

34. Bartocci M. Brain functional near infrared spectroscopy in human infants. Karolinska Institutet. Stockholm: Karolinska University Press, 2006.

35. Wolfberg AJ, du Plessis AJ. Near-infrared spectroscopy in the fetus and neonate. Clin Perinatol 2006;33:707-28.

36. Soul JS, du Plessis AJ. Near-infrared spectroscopy. Semin Pediatr Neurol 1999;6:101-10.

37. Duncan A, Meek JH, Clemence M, et al. Measurement of cranial optical path length as a function of age using phase resolved near infrared spectroscopy. Pediatr Res 1996;39:889-94.

38. Brazy JE, Lewis DV, Mitnick MH, Jobsis V. Noninvasive monitoring of cerebral oxygenation in preterm infants: Preliminary observations. Pediatrics 1985;75:217-25.

39. Tsuji M, duPlessis A, Taylor G, Crocker R, Volpe JJ. Near infrared spectroscopy detects cerebral ischemia during hypotension in piglets. Pediatr Res 1998;44:591-5.

40. Wyatt JS, Delpy DT, Cope M, Wray S, Reynolds EOR. Quantification of cerebral oxygenation and haemodynamics in sick newborn infants by near infrared spectrophotometry. Lancet 1986;328:1063-6.

41. Benaron DA, Hintz SR, Villringer A, et al. Noninvasive functional imaging of human brain using light. J Cereb Blood Flow Metab 2000;20:469-77.

42. Obrig H, Hirth $\mathrm{C}$, Junge-Hulsing JG, et al. Length of resting period between stimulation cycles modulates hemodynamic response to a motor stimulus. Adv Exp Med Biol 1997;411:471-80.

43. Obrig H, Wenzel R, Kohl M, et al. Near-infrared spectroscopy: Does it function in functional activation studies of the adult brain? Int J Psychophysiol 2000;35:125-42.

44. Obrig H, Villringer A. Near-infrared spectroscopy in functional activation studies. Can NIRS demonstrate cortical activation? Adv Exp Med Biol 1997;413:113-27.

45. Bartocci M, Winberg J, Papendiek G, Mustica T, Serra G, Lagercrantz $\mathrm{H}$. Cerebral hemodynamic response to unpleasant odors in the preterm newborn measured by near-infrared spectroscopy. Pediatr Res 2001;50:324-30.
46. Jöbsis FF. Noninvasive, infrared monitoring of cerebral and myocardial oxygen sufficiency and circulatory parameters. Science 1978;198:1264-7.

47. Hoshi Y. Functional near-infrared optical imaging: Utility and limitations in human brain mapping. Psychophysiology 2003;40:511-20.

48. Wolf M, Greisen G. Advances in near-infrared spectroscopy to study the brain of the preterm and term neonate. Clin Perinatol 2009;36:807-34.

49. Bassan H, Benson CB, Limperopoulos C, et al. Ultrasonographic features and severity scoring of periventricular hemorrhagic infarction in relation to risk factors and outcome. Pediatrics 2006;117:2111-8.

50. Roche-Labarbe N, Wallois F, Ponchel E, Kongolo G, Grebe R. Coupled oxygenation oscillation measured by NIRS and intermittent cerebral activation on EEG in premature infants. Neuroimage 2007;36:718-27.

51. van Alfen-van der Velden A, Claessen VPJ, Hopman JCW, Klaessens JHGM, Sengers RCA, Liem KD. Changes in cerebral oxygenation and hemodynamics during cranial ultrasound in preterm infants. Brain Dev 2009;31:427-34.

52. Fallon P, Roberts I, Kirkham FJ, et al. Cerebral hemodynamics during cardiopulmonary bypass in children using near-infrared spectroscopy. Ann Thorac Surg 1993;56:1473-7.

53. Roberts IG, Fallon P, Kirkham FJ, et al. Measurement of cerebral blood flow during cardiopulmonary bypass with near-infrared spectroscopy. J Thorac Cardiovasc Surg 1998;115:94-102.

54. duPlessis AJ, Newburger J, Jonas RA, et al. Cerebral oxygen supply and utilization during infant cardiac surgery. Ann Neurol 1995;37:488-97.

55. van Alfen-van der Velden AA, Hopman JC, Klaessens JH, Feuth T, Sengers RC, Liem KD. Effects of midazolam and morphine on cerebral oxygenation and hemodynamics in ventilated premature infants. Biol Neonate 2006;90:197-202.

56. Yanowitz TD, Potter DM, Bowen A, Baker RW, Roberts JM. Variability in cerebral oxygen delivery is reduced in premature neonates exposed to chorioamnionitis. Pediatr Res 2006;59:299-304.

57. Lemmers PM, Toet MC, van Bel F. Impact of patent ductus arteriosus and subsequent therapy with indomethacin on cerebral oxygenation in preterm infants. Pediatrics 2008;121:142-7.

58. Bartocci M, Winberg J, Ruggiero C, Bergqvist LL, Serra G, Lagercrantz $\mathrm{H}$. Activation of olfactory cortex in newborn infants after odor stimulation: A functional near-infrared spectroscopy study. Pediatr Res 2000;48:18-23.

59. Carlsson J, Lagercrantz H, Olson L, Printz G, Bartocci M. Activation of the right fronto-temporal cortex during maternal facial recognition in young infants. Acta Paediatrica 2008;97:1221-5.

60. Hoshi Y, Chen SJ. Regional cerebral blood flow changes associated with emotions in children. Pediatr Neurol 2002;27:275-81.

61. Becerra L, Harris W, Joseph D, Huppert T, Boas DA, Borsook D. Diffuse optical tomography of pain and tactile stimulation: Activation in cortical sensory and emotional systems. Neuroimage 2008;41:252-9.

62. Stevens BJ, Johnston CC, Horton L. Multidimensional pain assessment in premature neonates: A pilot study. J Obstet Gynecol Neonatal Nurs 1993;22:531-41.

63. Soul JS, Hammer PE, Tsuji M, et al. Fluctuating pressure-passivity is common in the cerebral circulation of sick premature infants. Pediatr Res 2007;61:467-73.

64. Lagercrantz H. The birth of consciousness. Early Hum Dev 2009;85(Suppl 1):S57-8.

65. Tsuji M, Saul JP, du PA, et al. Cerebral intravascular oxygenation correlates with mean arterial pressure in critically ill premature infants. Pediatrics 2000;106:625-32.

66. Soul JS, Taylor G, Wypij D, duPlessis AJ, Volpe JJ. Noninvasive detection of changes in cerebral blood flow by near-infrared spectroscopy in a piglet model of hydrocephalus. Pediatr Res 2000;48:445-9. 


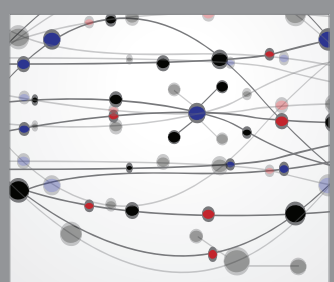

The Scientific World Journal
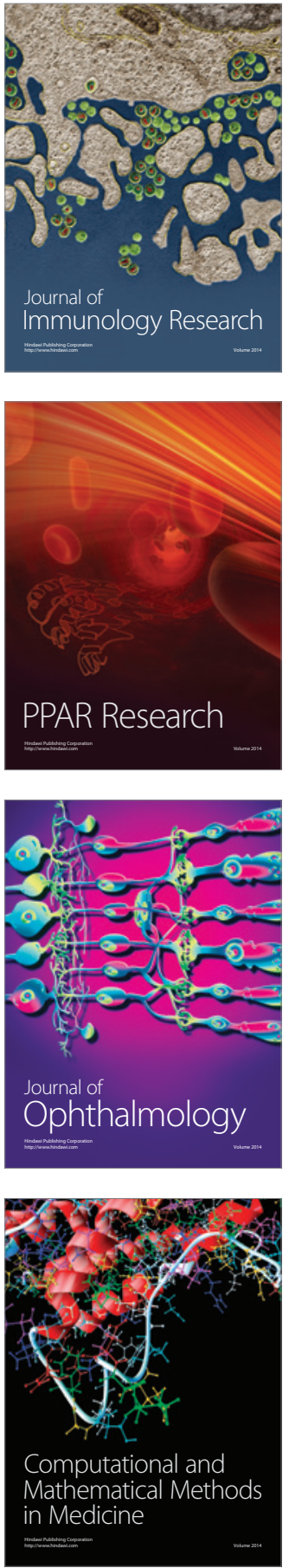

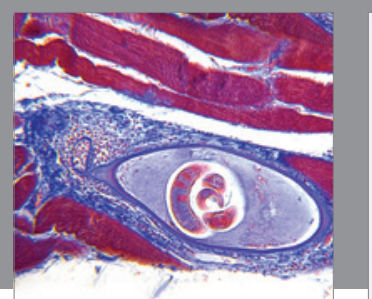

Gastroenterology Research and Practice

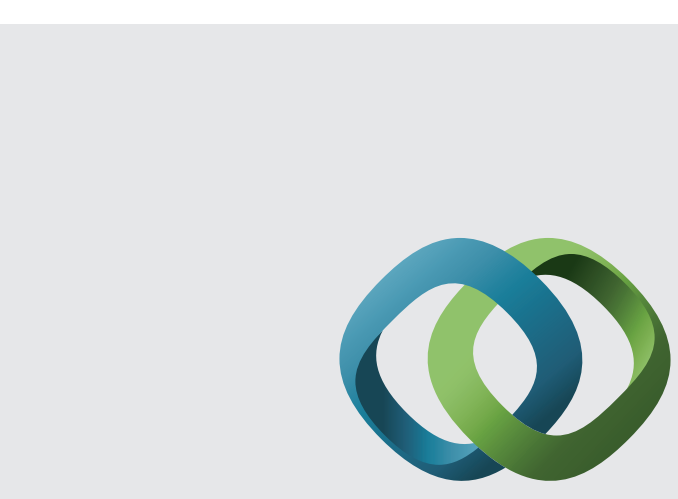

\section{Hindawi}

Submit your manuscripts at

http://www.hindawi.com
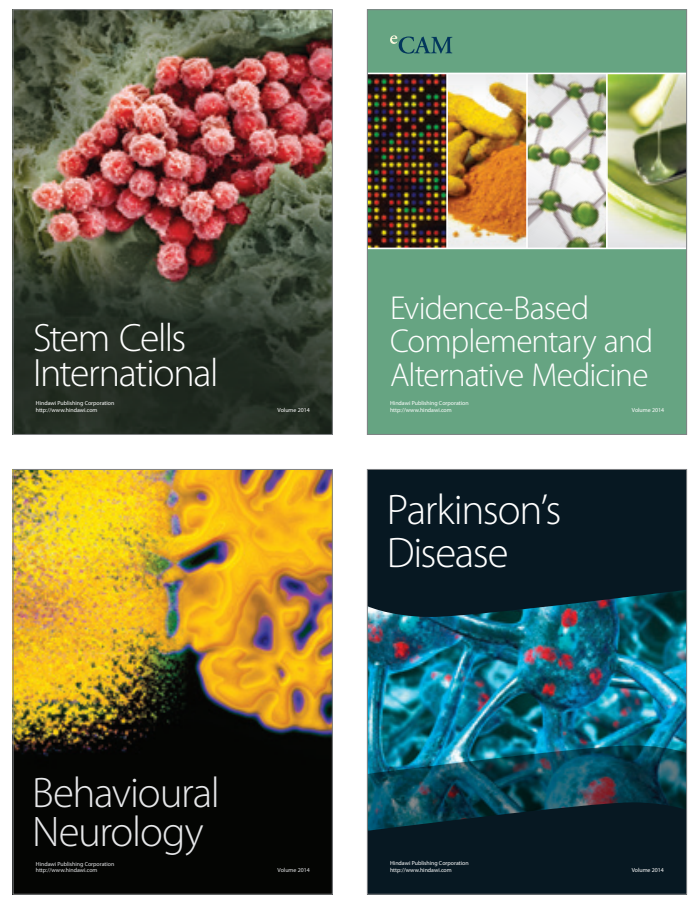
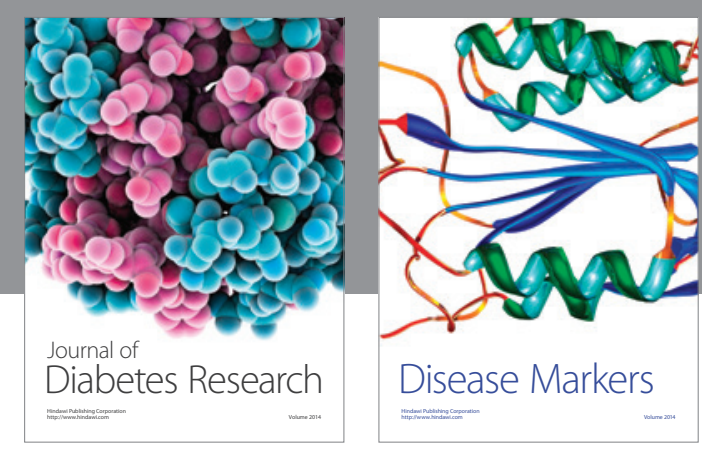

Disease Markers
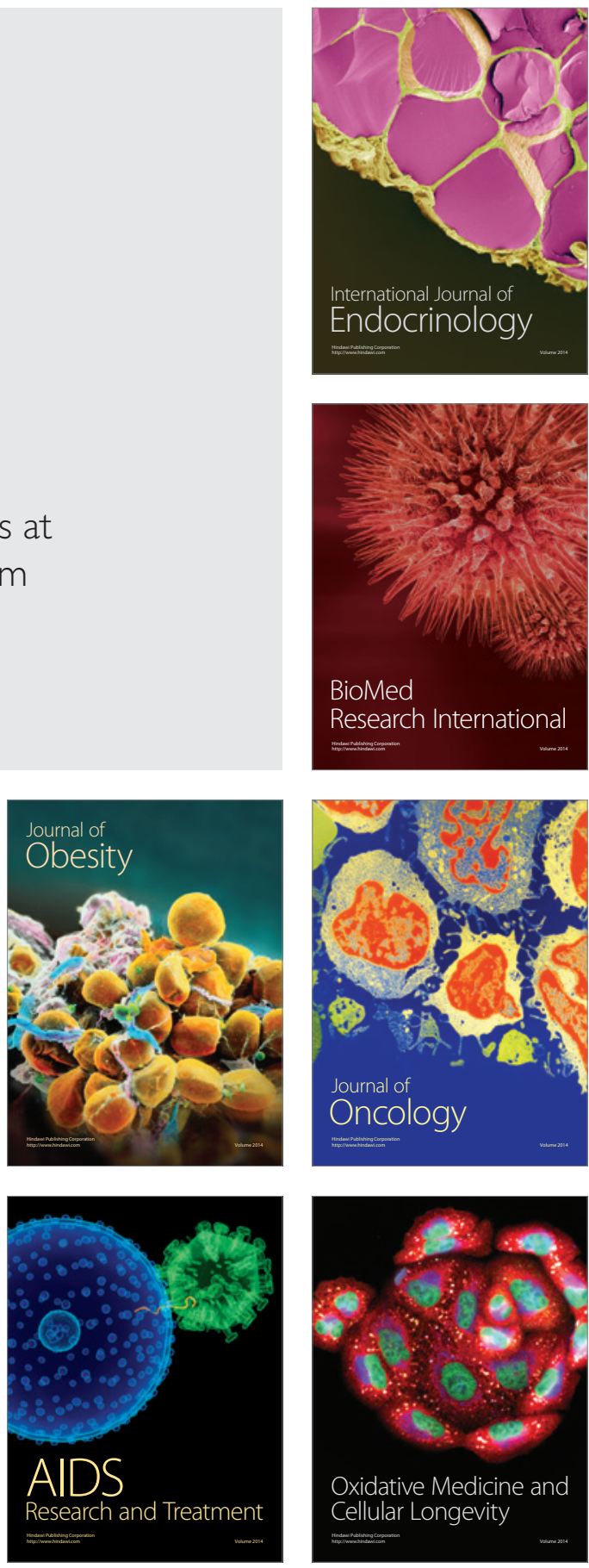